\title{
GOBIERNO URBANO Y URBANISMO EN BOGOTÁ Los barrios San Luis y El Campin (1938-1966)
}

\section{URBAN GOVERNMENT AND URBAN PLANNING IN BOGOTÁ The San Luis and El Campín neighborhoods (1938-1966)}

\author{
A. Eduardo Meza \\ Universidad Nacional de Colombia, Colombia \\ jemezac@unal.edu.co
}

\begin{abstract}
RESUMEN
La relación entre urbanismo y política ha sido problemática dado que el conocimiento sobre la ciudad incluye disciplinas como la arquitectura o la sociología. Este vínculo es estrecho ya que la ciudad y el urbanismo son fenómenos políticos en la medida que involucran actores con intereses diferenciales sobre el desarrollo urbano. Además, las intervenciones urbanas velan por la calidad de vida de sus habitantes, que comúnmente se cumplen a través de un gobierno urbano. Esto se evidencia en Bogotá, una ciudad que experimentó un acelerado crecimiento urbano a principios del siglo XX, lo que generó problemáticas urbanísticas y financieras. Como solución se intentó crear una estructura de gobierno urbano que, de paso, favorecería la modernización de la ciudad. Sin embargo, este objetivo se logró parcialmente ante la persistencia de dichas situaciones. Los barrios San Luis y El Campín son un reflejo de las dinámicas urbanísticas y políticoadministrativas que ocurrieron entonces.
\end{abstract}

Palabras clave: gobierno urbano, urbanismo, San Luis-El Campín, Bogotá.

Línea de investigación: 2: Ciudad y Proyecto.

Tema: Historia urbana e historia del urbanismo.

\footnotetext{
ABSTRACT

The relationship among town planning and politics has been problematic because knowledge about cities have included disciplines like architecture or sociology. This link is closed as city and town planning are political phenomena as in, they involve agents with different interests on the urban development. Thus, urban interventions ensure the life quality between the inhabitants, commonly carried out by an urban government. This is evident in Bogota, a city which experimented an accelerated urban growing at the beginning of 20th century, generating urbanistic and financial troubles. As a solution, creating an urban government structure was tried that, incidentally, should have impulse the modernization of this city. However, the objective was just
} 



\section{SIIOPAULO $15 \sim 17 \cdot$ LISBOA $25 \sim 26$ JUN 2020 \\ Seminário Internacional de \\ Seminario Internacional de Investigação em Urbanismo \\ Investigación en Urbanismo}

son reflejo de los cambios urbanos y político-administrativos que estaban ocurriendo. Esta serie de fenómenos permiten extraer algunas lecciones que podrían contribuir a un mayor entendimiento de la historia de la ciudad y la mejora de la planeación urbana en la actualidad.

El objetivo de esta ponencia es esclarecerlas a partir del análisis del rol de la planeación, la norma y el gobierno urbano en el desarrollo urbanístico de Bogotá entre 1938 y 1966, así como su influencia en la urbanización de los barrios San Luis y El Campín. Estos hacen parte de esta investigación dado que, al ubicarse en lo que fue la periferia norte de la ciudad en esos años, se convirtieron en un laboratorio para las nuevas ideas urbanísticas -a través del arquitecto y urbanista Karl Brunner- y las cuales intentarían cambiar la manera en la que se construían los barrios. Además, funcionaron como sectores articuladores de varios terrenos baldíos que existían a mediados de los años treinta, y se vieron beneficiados por la construcción del Estadio Municipal "Nemesio Camacho - El Campín".

\section{Urbanismo y política, una discusión pendiente. ¿Qué es el gobierno urbano?}

Entender la relación entre el urbanismo y la política parte del hecho de que las ciudades requieren de una estructura administrativa para la toma de decisiones pero, al mismo tiempo, son hechos políticos ya que en ellas se refleja la estructura de clases de la sociedad, y por ellas es que se decide sobre la vida y la muerte de las personas (Zambrano, 2002). De hecho, el urbanismo también se ha convertido en un fenómeno político ya que, a pesar de haberse atribuido un carácter científico, no ha sido políticamente neutral (Benévolo, 1967).

Las ciudades son un espacio potencial de conflictos por el acceso a recursos escasos -en especial el suelo-. Así como son útiles en el disciplinamiento y control de la población, también lo son para garantizar flujos económicos que fortalecen a las élites gobernantes. A través de políticas del uso del suelo, de promoción a la inversión e intervenciones urbanísticas -por ejemplo, de recuperación de sectores deteriorados- se logran cumplir estas funciones (Hall, 1996). Típicamente son llevadas a cabo por una estructura, o red si es preferible, compuesta por instituciones, normativas y actores de diverso tipo que se encargan de la gestión integral y completa de la ciudad. Este entramado se denomina en este artículo gobierno urbano, y se involucra en diversos asuntos que garantizan su funcionamiento, como la movilidad, el ordenamiento territorial, la protección del medio ambiente, educación, salud, entre otros, todo ello dirigido hacia un objetivo reconocido: mejorar la calidad de vida de los habitantes.

\section{Bogotá, gobierno urbano y urbanismo. Los barrios San Luis y El Campín.}

A pesar de que este concepto es reciente, se puede analizar históricamente. Bogotá es una ciudad que no ha sido estudiada desde una perspectiva politológica a pesar de que su desarrollo urbanístico también tuvo un componente político-administrativo. Hacia la década de 1910 su población escasamente había superado los cien mil habitantes, y no llegaba a los 400 mil treinta años después. En ese entonces, y posteriormente a la celebración del IV centenario de su fundación en 1938, las autoridades de la ciudad se preocuparon por los problemas que la urbanización causaba: hacinamiento en viviendas con poca ventilación y acceso a luz natural, sin disponibilidad de acueducto y alcantarillado, y poca o ninguna accesibilidad al centro de la ciudad (Gutiérrez, 2017). 



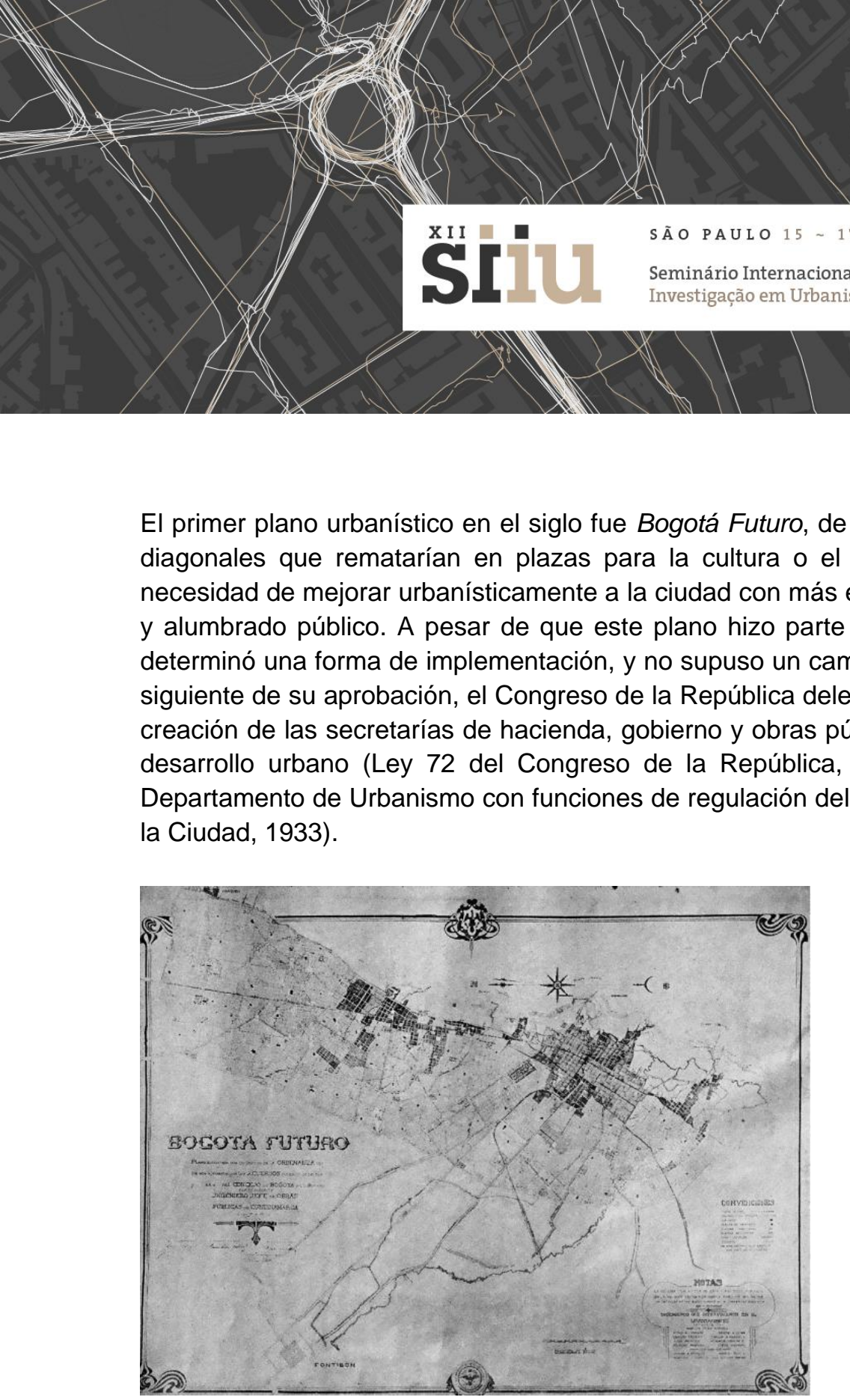

El primer plano urbanístico en el siglo fue Bogotá Futuro, de 1923. Proponía un ensanche hacia el norte con diagonales que rematarían en plazas para la cultura o el comercio minoritario (Alba, 2013). Afirmaba la necesidad de mejorar urbanísticamente a la ciudad con más eficaces servicios de agua potable, alcantarillado y alumbrado público. A pesar de que este plano hizo parte de la normativa, no se llevó a cabo porque no determinó una forma de implementación, y no supuso un cambio en las normas establecidas vigentes. Al año siguiente de su aprobación, el Congreso de la República delegó como funciones para el gobierno bogotano la creación de las secretarías de hacienda, gobierno y obras públicas, la cual sería importante en la gestión del desarrollo urbano (Ley 72 del Congreso de la República, 1926). Siete años después se conformaría el Departamento de Urbanismo con funciones de regulación del crecimiento urbano (Acuerdo 28 del Concejo de

Fig. 2: plano Bogotá Futuro (1925). Fuente: Alba (2013).

El crecimiento urbano se había profundizado hacia el norte, el sur y el occidente, dejando amplios espacios sin urbanizar. La función principal de Karl Brunner, el primer director del Departamento de Urbanismo, era la elaboración de un plan regulador que orientaría su desarrollo urbano pero, en vez de hacerlo, adquirió un rol importante en la celebración del cuarto centenario de la fundación de Bogotá, que se realizaría en 1938, estableciendo las obras públicas prioritarias, que se vieron reflejadas en el plan de obras de 1935. Se contemplaba la construcción de vías y redes de agua potable y alcantarillado para los barrios, la apertura de nuevas avenidas -como la Avenida Caracas, el saneamiento de los barrios obreros, y la construcción de un estadio municipal (Acuerdo 12 del Concejo Municipal, 1935). Como forma de fortalecimiento financiero, se aprobaron el impuesto predial, que gravaba la propiedad del suelo, y la tasa de valorización, aplicándose a los propietarios beneficiarios de obras públicas (Zambrano \& Barón, 2018). Ambos tenían un propósito común: beneficiar financieramente a la ciudad a partir de los procesos de urbanización.

Durante el IV centenario de la ciudad se inauguraron varias obras previstas. La Avenida Caracas se convirtió en una vía que favoreció el desarrollo de barrios como Teusaquillo. El estadio municipal, así como el estadio de la Universidad Nacional, fueron los escenarios que albergaron los primeros Juegos Bolivarianos, 


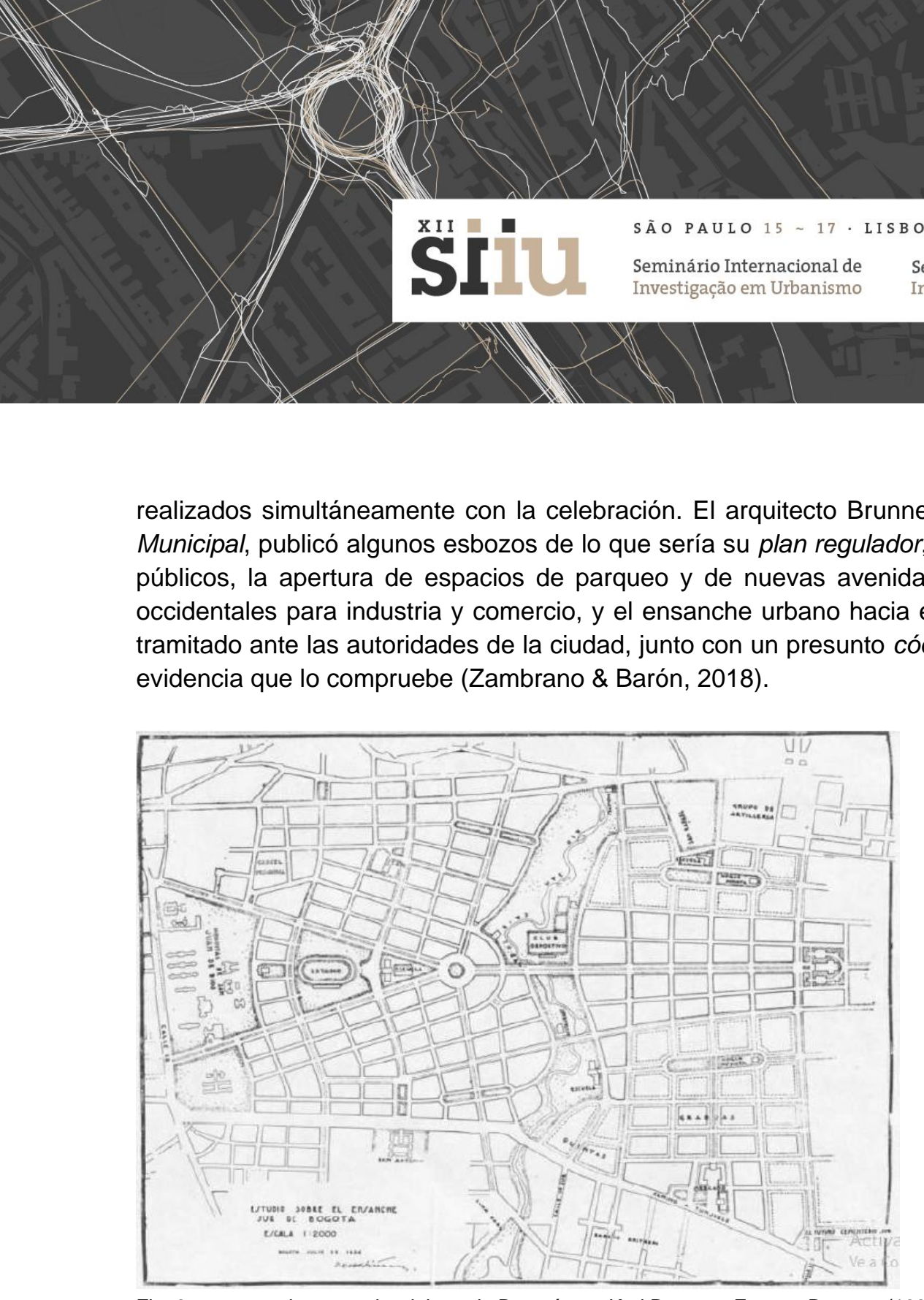

realizados simultáneamente con la celebración. El arquitecto Brunner, en una edición especial del Registro Municipal, publicó algunos esbozos de lo que sería su plan regulador, proponiendo la reubicación de edificios públicos, la apertura de espacios de parqueo y de nuevas avenidas, así como la fijación de los sectores occidentales para industria y comercio, y el ensanche urbano hacia el norte y el sur. Aunque afirma haberlo tramitado ante las autoridades de la ciudad, junto con un presunto código de urbanismo, no se ha encontrado

Fig. 3: proyecto de ensanche del sur de Bogotá, por Karl Brunner. Fuente: Brunner (1939).

Ante la intensificación del crecimiento urbano, las funciones del Departamento de Urbanismo quedaron desvirtuadas. En los años cuarenta la norma urbanística se fortaleció: en 1940 se aprobó el perímetro urbano, por fuera del cual estarían prohibidas las urbanizaciones, y se aumentó pronunciadamente el impuesto predial a los terrenos no urbanizados. Ambas medidas se tomaron para controlar la urbanización y hacer que los espacios baldíos fueran integrados a la ciudad (Acuerdo 15 del Concejo de la Ciudad, 1940). Cuatro años después se aprobó el primer acuerdo de zonificación, que dividía a la parte urbana en determinados usos del suelo, como residencial, comercial, cívico, industrial y de barrios obreros, entre otros (Acuerdo 21 del Concejo de la Ciudad, 1944). 


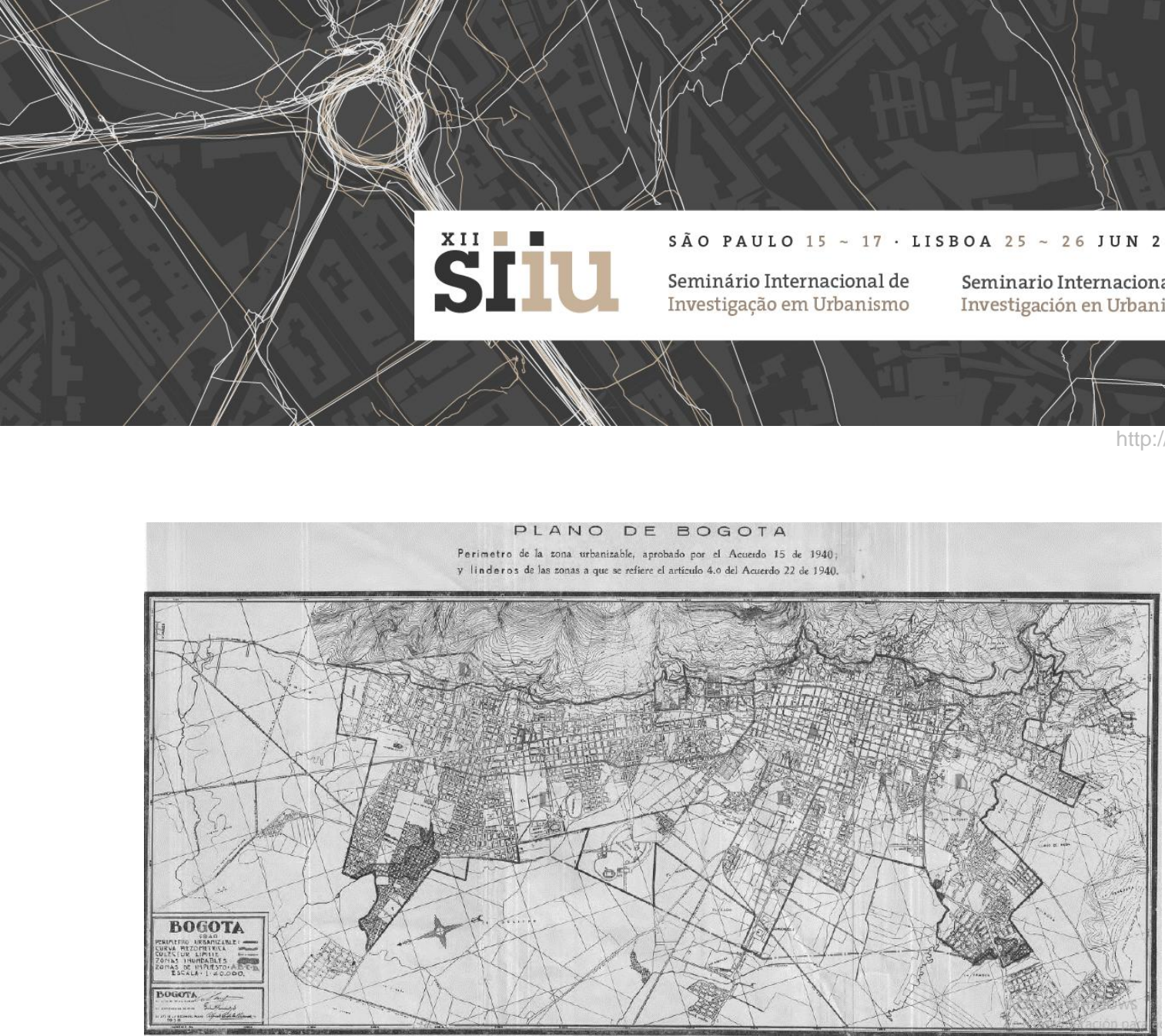

Fig. 4: plano del acuerdo 15 de 1940. La línea negra alrededor de la ciudad corresponde al perímetro urbano. Fuente: Registro Municipal (1940).

Después del plano Bogotá Futuro, el Plan Piloto, elaborado por Le Corbusier, y el Plan Regulador, fueron los planes urbanísticos que generaron más expectativas en la ciudad. Proponían una estricta zonificación de la ciudad de acuerdo con las cuatro funciones establecidas por la Carta de Atenas - habitar, trabajar, circular y cultivar tanto el cuerpo como el espíritu-, la apertura de avenidas, como la Avenida Cundinamarca, y la construcción del Centro Cívico, el cual albergaría la zona administrativo-política y de negocios de la ciudad (Le Corbusier, 1951 (2010)). Aunque contó con cierta oposición, especialmente por parte de vecinos que fueron excluidos del plan, varias circunstancias favorecieron su aprobación, como la destrucción de varios edificios durante los disturbios de El Bogotazo en 1948, y el cierre de todos los organismos legislativos del país al año siguiente. El alcalde de Bogotá lo aprobó unilateralmente mediante decreto en 1951, pero no tuvo en consideración a las instituciones que se encargarían de su implementación -excepto la Oficina del Plan Regulador- y los plazos para ejecutarlo (Cortés, 2007). 


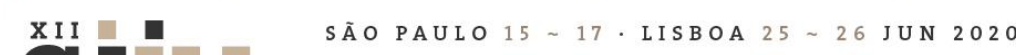

Seminário Internacional de

Seminario Internacional de Investigação em Urbanismo

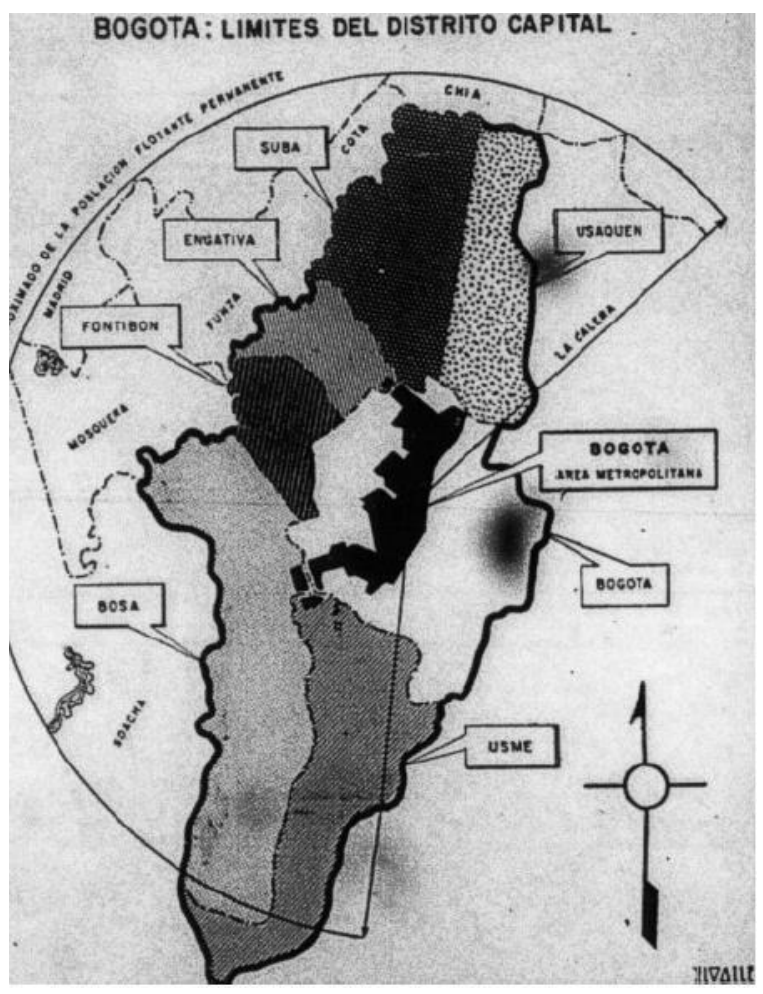

Fig. 6: Límites previstos para el Distrito Especial. Fuente: El Tiempo (1954, diciembre 16, pág. 1)

A pesar de que estos fueron los primeros logros, los problemas urbanos se acrecentaron sin ninguna solución. El periodo de La Violencia, una guerra civil que dejó miles de muertos en pocos años, junto con las mejoras en las vías nacionales, provocaron un crecimiento urbano intenso. Bogotá pasó de poco más de 700 mil habitantes en 1951 a más de un millón y medio en 1964 (Departamento Administrativo Nacional de Estadística, 1954, 1969). La mayoría de nuevos habitantes vivían en los que conocieron como tugurios, los cuales reproducían las problemáticas urbanas de principios del siglo: hacinamiento, insalubridad, poco acceso al transporte público, falta de equipamientos y ausencia parcial o total de servicios públicos básicos. Con la creación del Distrito Especial se esperaba que la ciudad actualizara las normas urbanísticas, así como la elaboración de nuevos planes urbanos. Los planes distritales de 1957 y 1958 proponían una zonificación que incluía sectores semirurales, y la extensión de varias avenidas, pero no fueron discutidos entonces (Saldarriaga, 2000). La antigua Oficina del Plan Regulador fue elevada a Departamento Administrativo de Planificación Distrital, lo que se tradujo en una estructura administrativa más compleja que incluía a profesionales de la ingeniera, las ciencias sociales, la arquitectura, entre otros (Departamento Administrativo de Planificación Distrital, 1964). Pero el crecimiento urbano era tan profundo que estos cambios administrativos no fueron suficientes para regularlo o impedirlo.

A finales de los años cincuenta el gobierno distrital estableció normas urbanas para cada uno de los barrios. En vez de formular un plan, el alcalde de Bogotá y el concejo distrital aprobaron un Plan Vial Piloto y una reglamentación más estricta a las urbanizaciones, ambos en 1961. El Plan Vial contemplaba la extensión de varias avenidas, entre ellas la Carrera 10 y la Avenida Caracas, así como la construcción de otras que al 



\section{SÃOPAULO15 17 LISBOA $25 \sim 26$ JUN 2020}

Seminário Internacional de

Seminario Internacional de Investigação em Urbanismo
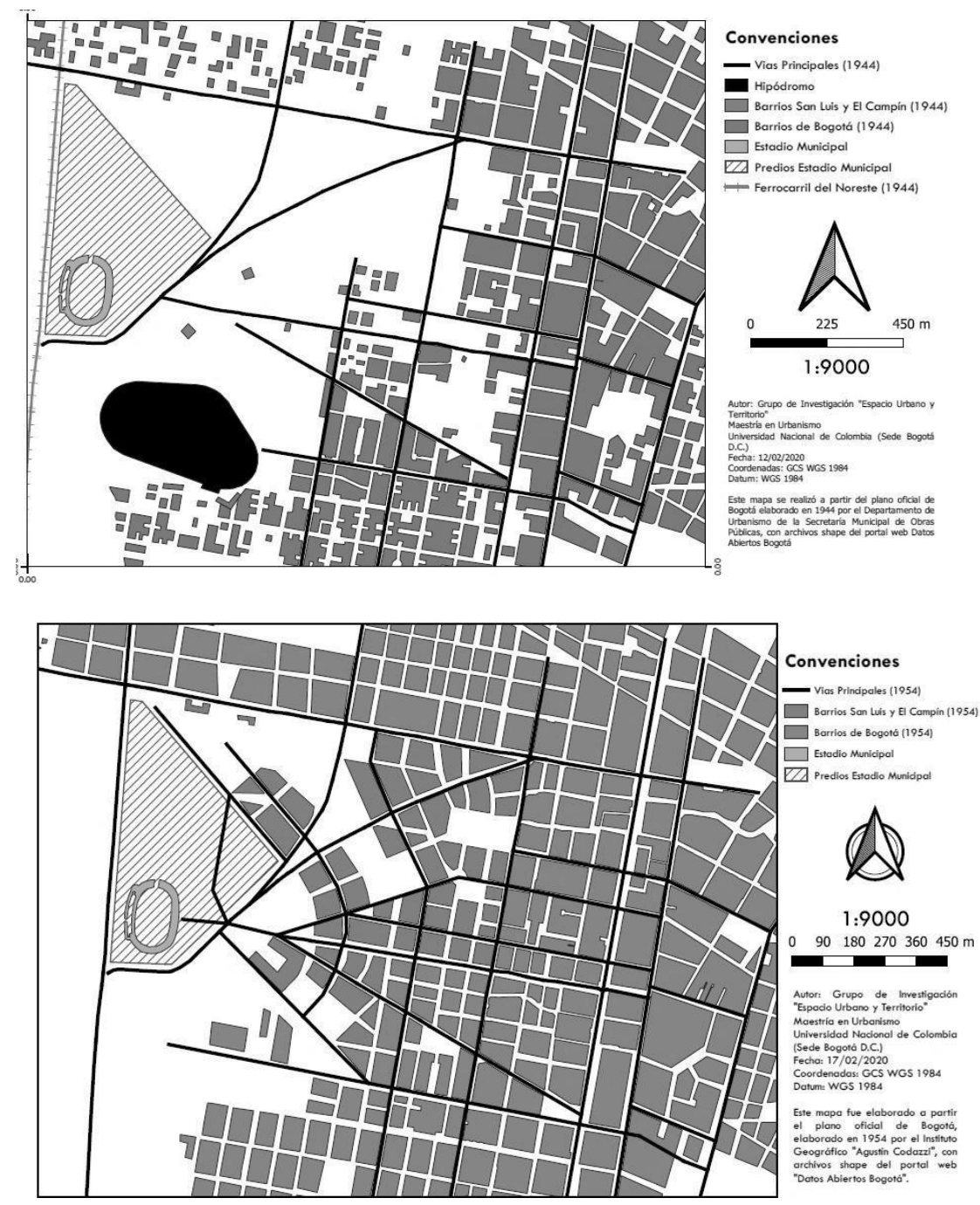

Fig. 7: San Luis y El Campín en 1944 (arriba) y 1954 (abajo). Fuente: Grupo de Investigación “Espacio Urbano y Territorio” (2020).

El desarrollo de los barrios se daría en un lapso aproximado de veinte años, entre los años 40 y 60 , y que fue facilitado normativas aprobadas entonces. El acuerdo 15 de 1940, al establecer el perímetro urbano, incluyó los terrenos en incipiente desarrollo, permitiendo implícitamente su urbanización. Luis Camacho, como concejal, fue proponente de este acuerdo, por lo que su aprobación sería beneficioso para él ${ }^{3}$. Cuatro años después, con el acuerdo sobre zonificación, se definió esta zona como "estrictamente residencial", prohibiendo la presencia de otros usos del suelo. El Plan Piloto consideró cambiar el trazado radial -que había

3 En los Anales del Concejo, ubicados en el Archivo de Bogotá (1940), Luis Camacho aparece como concejal. 


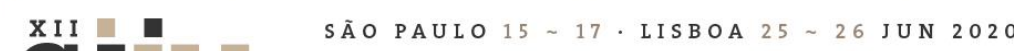

sido propuesto por Karl Brunner en su Manual de Urbanismo- por la extensión de las Calles 53 y 63 , y la apertura de la Avenida Cundinamarca -Carrera 30-, para rodearlos y "aislarlos" del tráfico vehicular. No obstante, la aprobación de dicho plan no implicó cambios en la norma urbanística vigente, por lo que el desarrollo de los barrios no tuvo casi contratiempos en los años 50 .

De acuerdo con la dinámica urbana que se presentaba, el barrio San Luis adquirió una vida jurídica mediante un decreto emitido en 1963, trazando los límites de los barrios, definiendo el uso del suelo - casi exclusivamente vivienda unifamiliar, pero con posibilidad de otras actividades de bajo impacto urbanístico -, índice de ocupación -solamente sería el 53\% del lote- y altura -dos pisos-. Realmente esta nueva normativa no pretendía establecer criterios a implementarse en nuevas urbanizaciones, sino acoplarse a la realidad existente. Administrativamente, los barrios San Luis y El Campín fueron beneficiados por la aplicación de la norma, en parte porque varios actores -entre ellos el Concejo Municipal- vieron en estas zonas un potencial sector de desarrollo urbano que no podía desaprovecharse. Actualmente, gracias a la arquitectura de sus viviendas, el trazado viario y su rol en la urbanización de Bogotá, pueden considerarse como barrios patrimoniales que hacen parte de la misma historia de la ciudad.

\section{Conclusiones}

La historia del gobierno urbano en Bogotá permite vislumbrar, desde una perspectiva histórica, algunas lecciones que pueden ser aprendidas para la planeación urbana en la actualidad: primero, una tradición colombiana es la excesiva confianza en las instituciones y las normas como únicas soluciones a los problemas urbanos. El urbanismo en estos tiempos debe ir de la mano con la norma porque, a menudo, la planeación y la normativa terminan siendo elementos sin articulación; segundo, relacionado con lo anterior, el exceso de normas relacionadas con el ordenamiento territorial sigue siendo un problema actualmente en Colombia y lo fue en ese entonces. La simplificación de los diferentes textos normativos podría ayudar a mejorar su entendimiento no solo por los expertos, sino también por las personas en general; y tercero, el desarrollo de San Luis y El Campín son ejemplos de que, a pesar de lo anterior, pueden confluir diversos elementos del gobierno urbano para que se logre un más articulado proceso de urbanización. Estos esfuerzos conjuntos son necesarios en la actualidad para superar los retos de la ciudad en el siglo XX.

\section{Referencias}

Acuerdo 28, por el cual se crea el Departamento de Urbanismo en la Secretaría de Obras Públicas Municipales. Aprobado por el Concejo Municipal el 11 de agosto de 1933. Régimen Legal de Bogotá D.C. (2020).

Acuerdo 12, sobre celebración del IV centenario de la fundación de Bogotá. Aprobado por el Concejo Municipal el 4 de septiembre de 1935. Registro Municipal (1935).

Acuerdo 15, por el cual se fija el perímetro urbanizable de la ciudad. Aprobado por el Concejo Municipal el 29 de febrero de 1940. Registro Municipal (1940).

Acuerdo 21, por el cual se divide el área urbanizable de Bogotá en varias zonas de destino. Aprobado por el Concejo Municipal el 30 de mayo de 1944. Régimen Legal de Bogotá (2018). 


\section{S SÃO PAULO $15 \sim 17 \cdot$ LISBOA $25 \sim 26$ JUN 2020

Acuerdo 30, por el cual se establece el procedimiento para la aprobación de lotificaciones. Aprobado por el Concejo Distrital el 30 de junio de 1961. Régimen Legal de Bogotá D.C. (2019).

Acuerdo 58, por el cual se fija el Plan Vial Piloto. Aprobado por el Concejo Distrital el 11 de agosto de 1961. Régimen Legal de Bogotá D.C. (2019).

ALBA, J. (2013). El plano Bogotá Futuro. Primer intento de modernización urbana. Anuario Colombiano de Historia Social y de la Cultura, 40(2), 179-208.

BENÉVOLO, L. (1967). Orígenes de la Urbanística Moderna. Buenos Aires: Editorial Tekné. BERDUGO, E. (2004). Nemesio Camacho Macías, un empresario del altiplano cundiboyacense:

1869-1929. Revista Escuela de Administración de Negocios, 51, 134-157.

BRUNNER, K. (1939). Manual de Urbanismo, Tomo I. Bogotá: Ediciones del Concejo.

CONSEJO NACIONAL DE PLANIFICACIÓN. (1953). Plan para Bogotá. Bogotá: Imprenta Municipal.

CORTÉS, R. (2007). Del urbanismo a la planeación en Bogotá (1900-1990). Esquema inicial y materiales para pensar la trama de un relato. Bitácora Urbano-Territorial, 11 (1), 160-207.

DÁVILA, J. (2000). Planificación y política en Bogotá. La vida de Jorge Gaitán Cortés. Bogotá: Instituto Distrital de Cultura y Turismo.

DEPARTAMENTO ADMINISTRATIVO DE PLANIFICACIÓN DISTRITAL. (1964). La planificación en Bogotá. Bogotá: Departamento Administrativo de Planificación Distrital.

FOUCAULT, M. (2006). Seguridad, territorio, población: curso en el Collège de France (1977-1978). Buenos Aires: Fondo de Cultura Económica.

GUTIÉRREZ, M. T. (2017). Ideología y prácticas higiénicas en Bogotá, en la primera mitad del siglo XX. Bogotá: Archivo Distrital.

HALL, P. (1996). Ciudades del Mañana. Historia del urbanismo en el siglo XX. Barcelona: Ediciones del Serbal.

HERNÁNDEZ, A. (2013). Elementos sociohistóricos intervinientes en la construcción de los estadios Alfonso López y El Campín para los primeros Juegos Bolivarianos: Bogotá, 1938. Revista Colombiana de Sociología, 36(1), 43-63.

JARAMILLO, S. (1980). Producción de vivienda y capitalismo dependiente. El caso de Bogotá. Bogotá: Universidad de los Andes.

LE CORBUSIER. (2010). Elaboración del Plan Regulador de Bogotá. Establecimiento del Plan Director por Le Corbusier en París, 1949-1950. En Le Corbusier en Bogotá, 1947-1951 (Tomo II) (266-273). Bogotá: Universidad de los Andes. Ley 88, sobre fomento del desarrollo urbano del municipio. Aprobado por el Congreso de la República el 26 de diciembre de 1947. Sistema Único de Información Normativa (2019). 


\section{SÃO PAULO15 17 LISBOA 25 26 JUN 2020

Manual de Régimen Urbano de Bogotá. (1942). Bogotá: Imprenta Municipal.

MEJÍA, G. (1997). Los itinerarios de la transformación urbana en Bogotá, 1820-1910. Anuario Colombiano de Historia Social y de la Cultura, 24, 101-137.

MONTOYA, J. W. (2018). De la ciudad hidalga a la metrópoli globalizada. Una historiografía urbana y regional de Bogotá. Bogotá: Universidad Nacional de Colombia.

SALDARRIAGA, A. (2000). Bogotá Siglo XX. Urbanismo, Arquitectura y Vida Urbana. Bogotá: Departamento Administrativo de Planeación Distrital.

WIENER, P. L., \& SERT, J. L. (1953). El Plan Regulador. Anales de Ingeniería, LVIII(640), 7-107. ZAMBRANO, F. (2002). La ciudad en la historia. En TORRES, C.; VIVIESCAS, F.; y PÉREZ, E. (coord.), La ciudad: hábitat de diversidad y complejidad (121-148). Bogotá: Universidad Nacional de Colombia.

ZAMBRANO, F., y BARÓN, A. (2018). 1938. El sueño de una capital moderna. Bogotá: Instituto Distrital de Patrimonio Cultural.

\section{Fuentes Electrónicas}

ALVARADO, A. (31 de marzo de 2015). Cuando la gente en Colombia se moría de gripa. Recuperado el 19 de febrero de 2020, de El Tiempo: https://www.eltiempo.com/archivo/documento/CMS- 15495335

DEPARTAMENTO ADMINISTRATIVO NACIONAL DE ESTADÍSTICA. (1954). Censo de Población de 1951. Recuperado el 13 de septiembre de 2018, de Departamento Administrativo Nacional de Estadística: http://biblioteca.dane.gov.co/media/libros/LD_809_1951_V_1.PDF

DEPARTAMENTO ADMINISTRATIVO NACIONAL DE ESTADÍSTICA. (1969). XIII Censo General de Población y II de Edificios y Viviendas. Recuperado el 21 de octubre de 2018, de Departamento Administrativo Nacional de Estadística:

http://biblioteca.dane.gov.co/media/libros/LB_808_1964.PDF

GARGANTINI, D., PERESINI, N., y ALVARADO, M. (2017). Ciudad en disputa: representaciones y estrategias de articulación-acción de actores sociales en el gobierno del suelo urbano. El caso de la ciudad de Córdoba. Recuperado el 11 de junio de 2019, de Universidad Nacional de Villa María: http://biblio.unvm.edu.ar/opac_css/doc_num.php?explnum_id=1668 


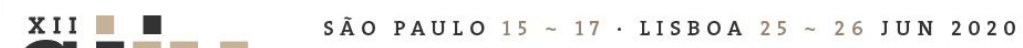

Seminário Internacional de Investigação em Urbanismo
Seminario Internacional de Investigación en Urbanismo 